\title{
Preparation and study of porous Si surfaces obtained using the electrochemical method
}

\author{
V.G. Lytovchenko ${ }^{1 *}$, T.I. Gorbanyuk ${ }^{1}$, V.P. Kladko $^{1}$, A.V. Sarikov ${ }^{1}$, N.V. Safriuk ${ }^{1}$, L.L. Fedorenko ${ }^{1}$, \\ S. Ašmontas ${ }^{2}$, J. Gradauskas², E. Širmulis ${ }^{2 *}$, O. Žalys ${ }^{2}$ \\ ${ }^{I} V$. Lashkaryov Institute of Semiconductor Physics, \\ National Academy of Sciences of Ukraine \\ 45, prospect Nauky, 03680 Kyiv, Ukraine \\ ${ }^{2}$ Center for Physical Sciences and Technology, \\ Sauletekio av., 3, LT-10257, Vilnius, Lithuania

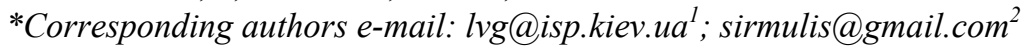

\begin{abstract}
Review of original results concerning electrochemical formation of porous Si layers and investigation of properties inherent to the formed layers has been presented. The results related with observation of changes in pores' morphology depending on the etching conditions, correlation of morphology of the porous layers with their surface composition, photoluminescence and structural characteristics, catalytic activity of porous Si based MIS structures as well as theoretical modeling of the kinetics and mechanisms of the porous Si growth have been described.
\end{abstract}

Keywords: porous Si, electrochemical etching, gas sensing, MIS structure, photoluminescence, X-ray diffraction, kinetic modeling.

Manuscript received 03.10.17; revised version received 02.11.17; accepted for publication 07.12.17; published online 07.12.17.

\section{Introduction}

First demonstrated in 1990, porous silicon (PS) layers were formed on crystalline silicon (c-Si) wafers using electrochemical and chemical etching in concentrated solution of $\mathrm{HF}$ and $\mathrm{C}_{2} \mathrm{H}_{5} \mathrm{OH}$ [1]. These layers exhibited photoluminescent properties as a semiconductor with the direct energy band gap [2]. Due to IUPAC guidelines, porous silicon has been classified depending on pore size as microporous, mesoporous and macroporous. Micropores have width smaller than $2 \mathrm{~nm}$. The width of mesopores ranges between 2 and $50 \mathrm{~nm}$. Macropores are wider than $50 \mathrm{~nm}$. Many works demonstrate that the surface of freshly prepared PS is passivated by $\mathrm{Si}$ hydrides and fluorides. However, long time exposure of the porous Si layers to air leads to slow oxidation of the
PS surface. The presence of silicon oxide on the PS surface stimulates the shift of PL spectra to the shorter (blue) wavelength range. The structural data for PS are very complicated. Some published works indicate that highly porous crystalline silicon layers consist of $\mathrm{Si}$ columns and pores or of isolated nanocrystallites [3]. On the other hand, PS may be considered as a system of interconnected quantum wells, the so-called "quantum sponge" [4-6]. It is now well established that the electropolishing of silicon begins for the current density $j>j_{\text {crit }}$ [7-9]. At the same time, anodic dissolution of $p$ type $\mathrm{c}-\mathrm{Si}$ in fluoric acid solution leads to fabrication of mesoporous silicon. In this work, the structure and composition are studied in detail depending on $\mathrm{HF}$ concentration in the electrochemical solution. It is shown that decrease in HF concentration at a constant current 
density leads to the conversion of the structures from meso-PS to macro-PS. Thus, the composition of PS surface is significantly changed (polymerized hydride silicon coverage on meso-PS surface transforms to silicon oxide on the macro-PS surface). Also, the shift of PL peak has been observed.

\section{Chemical reactions governing the electrochemical dissolution of crystalline $\mathrm{Si}$}

Electrochemical formation of porous silicon layers involves reactions of $\mathrm{Si}-\mathrm{Si}, \mathrm{Si}-\mathrm{H}, \mathrm{Si}-\mathrm{O}$, and $\mathrm{Si}-\mathrm{F}$ bonds at the surface of crystalline silicon wafers. As a rule, $\mathrm{Si}-$ $\mathrm{H}$ species passivate the silicon surface in aqueous solutions, while the $\mathrm{Si}-\mathrm{F}$ bond is highly reactive $[10,11]$. Electronegative elements such as $\mathrm{O}$ and $\mathrm{F}$ form more polar $\mathrm{Si}-\mathrm{X}$ bonds. The surface of freshly prepared PS is covered with a passivating layer of $\mathrm{Si}-\mathrm{H}$ bonds and small quantities of $\mathrm{Si}-\mathrm{F}$ and $\mathrm{Si}-\mathrm{O}$ species. Silicon is thermodynamically unstable in water and/or air, and it reacts spontaneously to form an oxide layer:

$\mathrm{Si}+\mathrm{O}_{2} \rightarrow \mathrm{SiO}_{2}$.

$\mathrm{SiO}_{2}$ is an insulator that forms passivating films on c-Si. Preparation of porous silicon thus requires an additive into the solution to dissolve silicon oxide and allow electrochemical corrosion to continue. The $\mathrm{Si}-\mathrm{F}$ bond is stronger than $\mathrm{Si}-\mathrm{O}$, and the $\mathrm{Si}-\mathrm{F}$ bond enthalpy drives the main chemical dissolution reaction preparing porous silicon. In the presence of aqueous $\mathrm{HF}, \mathrm{SiO}_{2}$ spontaneously dissolves in the form of $\mathrm{SiF}_{6}{ }^{2-}$ :

$\mathrm{SiO}_{2}+6 \mathrm{HF} \rightarrow \mathrm{SiF}_{6}^{2-}+2 \mathrm{H}^{+}+2 \mathrm{H}_{2} \mathrm{O}$.

The interaction reaction of $\mathrm{SiO}_{2}$ with $\mathrm{HF}$ is a common industrial reaction. It is used to remove $\mathrm{SiO}_{2}$ masking layers in the processing of silicon integrated circuits in microelectronics. The silicon hexafluoride ion $\left(\mathrm{SiF}_{6}{ }^{2-}\right)$ is a stable dianion that is highly soluble in water. Thus, fluoride is the most important additive used in preparation of porous silicon layers, dissolving the insulating silicon oxide that would otherwise cut down the reaction of electrochemical corrosion $[12,13]$. The freshly etched surface of porous silicon is covered primarily with hydride species. Residual oxides and/or fluorides are removed by the HF electrolyte. Three types of silicon hydrides are on the porous silicon surface: $\mathrm{SiH}, \mathrm{SiH}_{2}$, and $\mathrm{SiH}_{3}$. When silicon is electrochemically etched in HF solution, $\mathrm{Si}$ surface becomes terminated with $\mathrm{H}$ atoms. The surface $\mathrm{Si}-\mathrm{H}$ species are not readily removed in HF acid, and these must be chemically oxidized to continue the silicon dissolution reaction.

A two-electrode electrochemical cell is usually used to prepare porous silicon. In this case, silicon anode is one of the working electrodes, and the oxidation reaction takes place on its surface. The cathode counterelectrode is typically platinum. The main oxidation and reduction half-reactions occurring during formation of porous silicon are as follows:

$\mathrm{Si}+6 \mathrm{~F}^{-}+2 \mathrm{H}++2 \mathrm{~h}^{+} \rightarrow \mathrm{SiF}_{6}^{2-}+\mathrm{H}_{2}$,

$2 \mathrm{H}+2 \mathrm{e}^{-} \rightarrow \mathrm{H}_{2}$.

The electrochemical reaction (4) on the platinum electrode is reduction of protons to hydrogen gas molecules. The reaction (3) is the main half-reaction responsible for porous $\mathrm{Si}$ formation. The most important factor during pores formation is the availability of valence band holes. This is primarily determined by the doping level of silicon substrate, but it can be also influenced by illumination, HF concentration, and the applied electric field. As a rule, crystallographically oriented pores are generally formed at low current densities and can appear as facet-like structures in crosssectional scanning electron microscope (SEM) images, while "current-line-oriented-pores" or "current pores" are formed at higher current densities. These pores are usually oriented along the normal to the surface plane of Si wafer. There is a high concentration of valence band holes in $p$-type silicon, and the etching is not limited by their availability. In $n$-type silicon, however, the deficiency of valence band holes limits the density of pores. In this case, the surface of $n$-type silicon should be illuminated for additional generation of holes in the valence band.

\section{Formation of mesopores and macropores in p-type Si wafers}

A part of the investigated PS layers was formed on (100) oriented boron doped Si wafers $\left(N_{A}=4 \times 10^{15} \mathrm{~cm}^{-3}\right)$ by electrochemical etching using the solutions of $\mathrm{HF}(48 \%): \mathrm{C}_{2} \mathrm{H}_{5} \mathrm{OH}$ with the ratios $4: 1$ and $1: 4$ at the current density $j_{P S}=30 \mathrm{~mA} / \mathrm{cm}^{2}$ [14-17]. Ethanol was added to HF acid to minimize hydrogen bubble formation during the anodization process. The thickness of the formed PS layers (in the range of 5 to $20 \mathrm{~nm}$ ) was measured by Dektak 3030 auto II profilometer followed by stripping. The PS porosity $(\sim 60 \%)$ was calculated using the gravimetric method. The stripping of PS films for thickness and porosity measurements was carried out in $1 \mathrm{M} \cdot \mathrm{KOH}$ aqueous solutions. The mean pore size $(2 \ldots 8 \mathrm{~nm})$ and specific area $\left(\sim 500 \mathrm{~m}^{2} / \mathrm{g}\right)$ of free standing meso-PS films were obtained by the low-temperature nitrogen adsorption (BET) method using the ASAP 2405 microanalyser. Chemical composition of the PS layers was studied using IR-spectroscopy in a broad range of wavenumbers $\left(400 \ldots 4000 \mathrm{~cm}^{-1}\right)$ by using the Fourier transform spectrometer (Bruker). SEM and AFM investigations were carried out to study the PS layer microstructure. Morphology of porous Si on the $n$-type Si wafers is characterized by the presence of macropores. PS layers prepared on the highly doped $p^{+}$- or $n^{+}-\mathrm{Si}$ wafers are mesoporous, and $p$-type $\mathrm{Si}$ yields meso- and/or 
microporous silicon. It should be noted that different morphologies of the porous Si layers result from different pores formation mechanisms. The overall structure of the PS layers very strongly depends on the HF concentration in the electrolyte. The AFM image of PS layer can be seen in Fig. 1a. It appears that increasing the concentration of HF causes meso-PS on $p$-type of silicon substrate with the level of doping $\sim 10^{15} \ldots 10^{16} \mathrm{~cm}^{-3}$. The prepared PS samples were rinsed in $\mathrm{H}_{2} \mathrm{O}$ or $\mathrm{C}_{2} \mathrm{H}_{5} \mathrm{OH}$ after the electrochemical etching. In the case of rinsing in water, PS films possess the two-layer structure (Fig. 1b) caused by its interaction with $\mathrm{H}_{2} \mathrm{O}$ during washing $[14,15]$. For the meso-PS layers, the porosity is about $60 \%$, and the average size of the pores determined by BET method is in the range of 3 to $8 \mathrm{~nm}$.

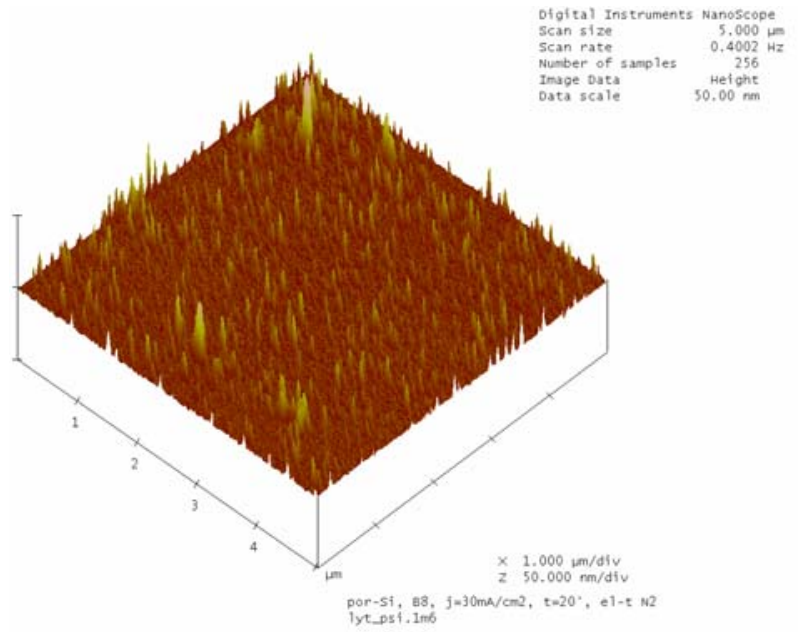

(a)

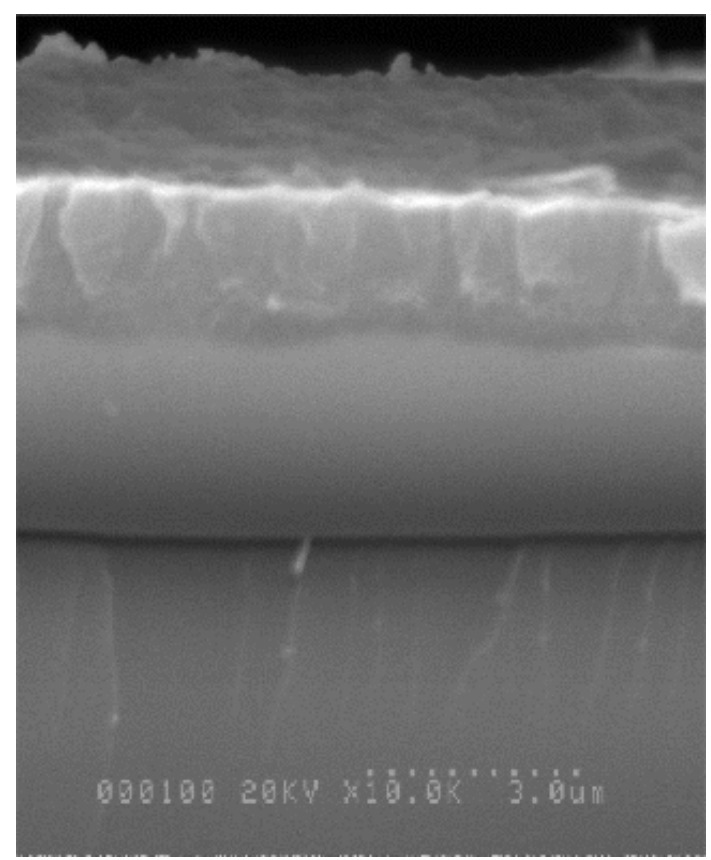

(b)

Fig. 1. AFM and SEM images of mesoporous silicon: (a) surface, (b) cross-section.
Macro-PS layers fabricated in diluted HF solution exhibit mat surface (Fig. 2) and high porosity $(\sim 80 \ldots 90 \%)$. The process of the macropores formation during the electrochemical etching of $\mathrm{Si}$ may be presented as follows. The disproportionation reaction first induces formation of supersaturation of the electrolyte with $\mathrm{Si}$ atoms during an incubation period [17]. Then, deposition of Si atoms on the c-Si surface starts, and microcrystalline silicon columns form simultaneously with the substrate etching. Both these processes take place simultaneously due to high electric resistance of the microcrystalline $\mathrm{Si}$ columns. These experimentally observed phenomena were also confirmed by the fact that after the macro-PS layer was removed in the diluted $\mathrm{KOH}$, the pores remained on the c-Si surface (Fig. 3).

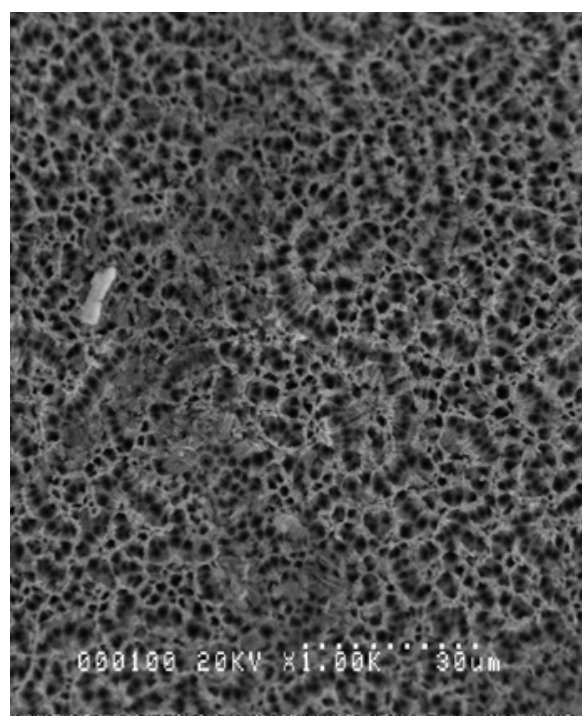

(a)

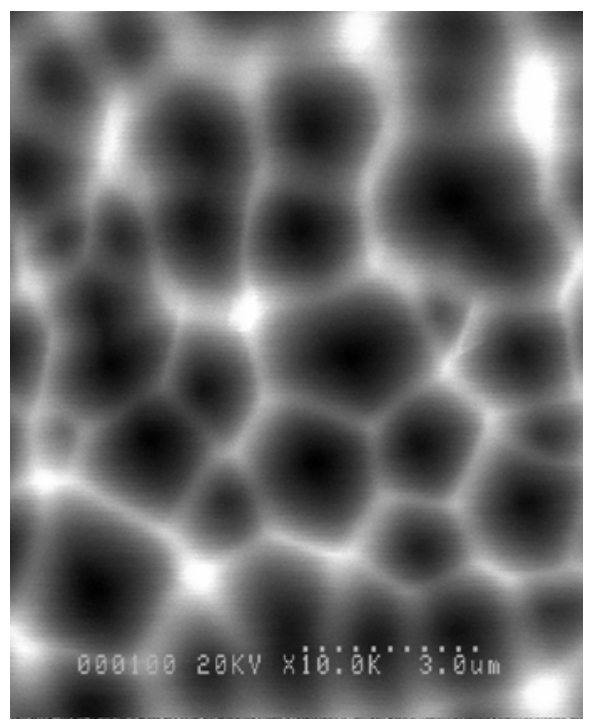

(b)

Fig. 2. (a), (b) SEM images of macroporous surface silicon formed on $p$-type silicon wafer. 


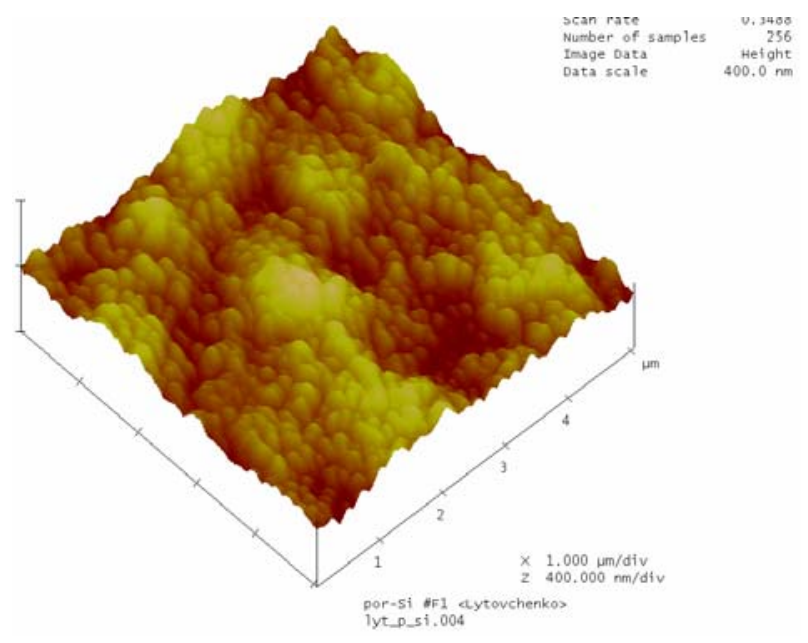

Fig. 3. AFM images of surface silicon wafer after removal of macro-PS layer.

Formation of polymerized meso-PS films may be possible due to a chain reaction. This mechanism of the meso-PS formation occurs only in electrolyte with high HF concentrations (60 to $80 \%$ ) and at sufficiently low current densities (5 to $30 \mathrm{~mA} / \mathrm{cm}^{2}$ ) $[15,17,18]$. In particular, siloxane polymer has been formed on the meso-PS surface [16, 17]. It is also important to note that definition of pore sizes as well as measurements of the refraction index and specific area of PS surface by BET method need free standing PS films. The meso-PS films easily peel off from the $\mathrm{c}-\mathrm{Si}$ surface at the current density $j \gg>j_{P S}\left(j_{P S}=30 \mathrm{~mA} / \mathrm{cm}^{2}\right)$. However, in the case of macro-PS layers the electropolishing is initiated under this condition. Furthermore, meso-PS interacts with water during washing, which causes hydrogen emission. In contrast, the macro-PS layers rarely interact with water but are easily dissolved in $5 \% \mathrm{KOH}$ solution. Different origins of the meso-PS and macro-PS have also been confirmed by the following facts: in the first case, it is possible to obtain polymerized meso-PS films, while in the second case microcrystalline Si columns are coupled with pores in the silicon substrate. Comparison of IR spectra of c-Si and macro-PS has demonstrated (Fig. 4) that in both cases the $\mathrm{Si}-\mathrm{H}$ valence vibrations is absent. However, Si oxide bonds are present in macroPS layers in a large amount, so that their surfaces are strongly oxidized. The IR absorption between 2300 and $2000 \mathrm{~cm}^{-1}$ of the meso-PS films appears due to $\mathrm{Si}-\mathrm{H}$ valence vibrations. The initial $\mathrm{SiH}$ band around $2100 \mathrm{~cm}^{-1}$ can be decomposed into three peaks near 2080,2110 and $2140 \mathrm{~cm}^{-1}$, which are generally ascribed to $\mathrm{SiH}, \mathrm{SiH}_{2}$ and $\mathrm{SiH}_{3}$ modes, respectively. Appearance of the $\mathrm{O}_{\mathrm{x}} \mathrm{SiH}$ band indicates formation of $\mathrm{SiH}$ groups connected to one, two or three oxygen atom with typical positions at 2140,2210 and $2270 \mathrm{~cm}^{-1}$, respectively. The analysis of the low wavenumber region of meso-PS spectra $\left(<1000 \mathrm{~cm}^{-1}\right)$ is more difficult since the valence vibrations $\left(\mathrm{SiF}_{\mathrm{y}}\right)$ of $\left(\mathrm{SiH}_{\mathrm{x}} \mathrm{F}_{\mathrm{y}}\right)$ molecules occur in the same frequency range as for the deformation vibrations $\left(\mathrm{SiH}_{\mathrm{x}}\right)$ in these molecules. We usually assign the peak at $910 \mathrm{~cm}^{-1}$ to the $\mathrm{SiF}$ valence vibrations [18]. Indeed, SIMS spectra confirm the presence of the fluorinated hydride surface of freshly etched meso-PS layers $[15,17]$. The $\mathrm{Si}-\mathrm{O}$ valence vibration in meso-PS layers does not need to be taken into account. However, the progressive oxidation takes place.

\section{Adsorption properties of mesoporous silicon}

Gas sensitive structures based on meso-PS were formed with top catalytically active electrodes $\left(\mathrm{Pd}, \mathrm{WO}_{3}\right)$ on MIS structures shown in Fig. 5. In this case, the $I-V$ characteristics shown in Fig. 6 were measured for the registration of response signal under the action of $\mathrm{H}_{2} \mathrm{~S}$ in $\mathrm{N}_{2}$ atmosphere.

We consider briefly a simplified model of the PS based MIS-structure using the energy band diagram of the diode structures. In fact, it is known that the metal porous Si structure is a very complicated Schottky-like structure consisting of numerous connected in parallel metal - PS junctions $[14,15,18,19]$.

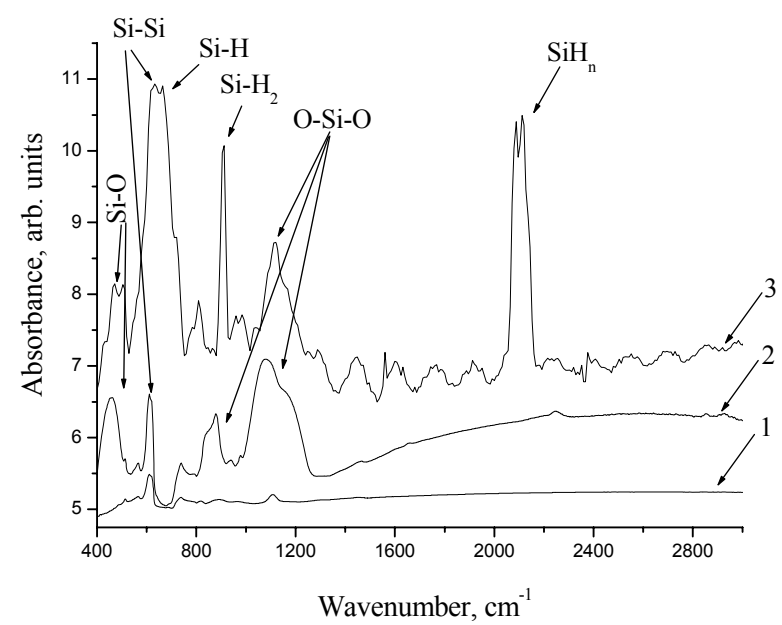

Fig. 4. IR-spectra of c-Si, meso-PS and macro-PS prepared on $p$-type Si wafer.

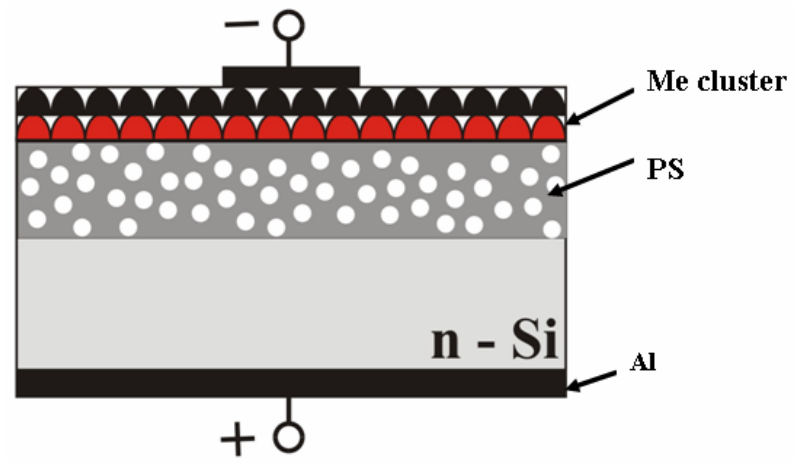

Fig. 5. Schematic representation of MIS-structure based on PS with catalytically active top electrode. 


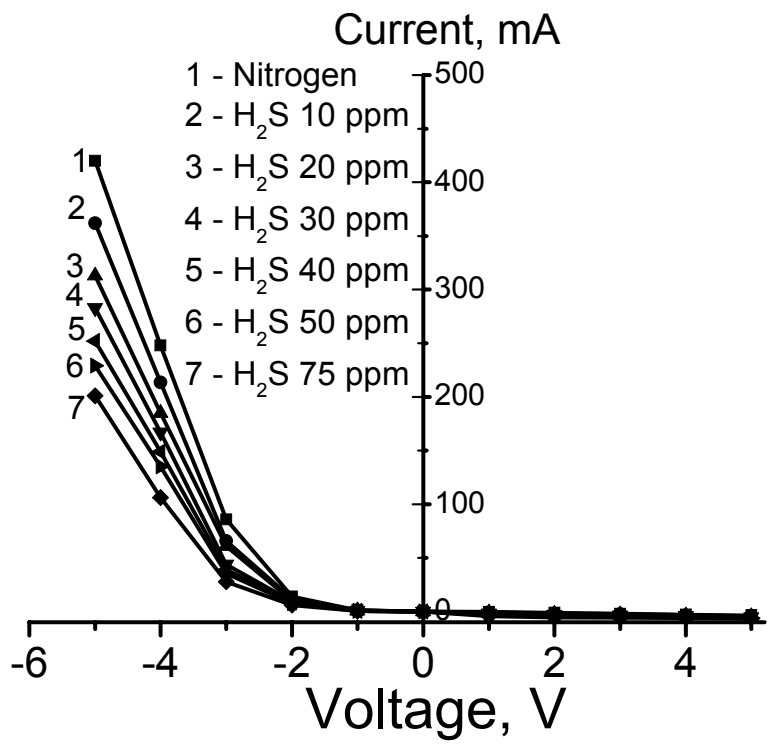

Fig. 6. Effect of $\mathrm{H}_{2} \mathrm{~S}$ on $I-V$ characteristics of MIS-structures based on meso-PS on $p$-type silicon substrate.

The forward current-voltage $(I-V)$ characteristic of a non-ideal Schottky diode behavior in the case of thermionic emission model is:

$$
I=I_{S}\left[\exp \left(\frac{q U_{D}}{n k T}\right)-1\right],
$$

where $q$ is the elementary charge, $U_{D}$ - voltage applied across the Schottky diode, $k$ denotes the Boltzmann constant, $n$ stands for the ideality factor, and $T$ is the absolute temperature.

$I_{s}$ can be expressed as

$$
I_{S}=A_{e f f} A^{* *} T^{2} \times \exp \left(-\frac{q \phi_{B}}{k T}\right),
$$

where $A_{\text {eff }}$ is the effective area of the diode, $A^{* *}$ $\left(\sim 8.6 \mathrm{~cm}^{-2} \mathrm{~K}^{-2} \mathrm{~A}\right)$ stands for the Richardson constant, $\phi_{B}$ denots the Schottky barrier height.

We want to point out that all the responses observed in this study may be characterized by the Schottky barrier height $\phi_{B}$ (see Eq. (6)), which depends on the gas environment.

Gas sensitivity of Pd/PS/Si Schottky diode based on the PS under $\mathrm{H}_{2}$ adsorption has been studied with and without polymer film on the porous surface for $p$-type silicon substrates. Without polymer film and with negative bias on the metal electrode with respect to semiconductor, the current direction is assumed as forward. In this regime, the Schottky diode is not sensitive to the test gas adsorption. In this case, the reverse branch of the $I-V$ characteristic shifts under the action of $500 \mathrm{ppm} \mathrm{H}_{2}, \mathrm{H}_{2} \mathrm{O}$ and/or $\mathrm{O}_{2}$ in nitrogen, and this shift can reach a substantial magnitude at the applied bias voltages 0.9 to $1.2 \mathrm{~V}$. One explanation of the observed $\mathrm{H}_{2}$ and $\mathrm{H}_{2} \mathrm{O}$ sensitivity suggests that hydrogen or water molecules dissociate rapidly due to catalytic action of Pd producing free hydrogen atoms. Then, the hydrogen atoms penetrate through the Pd film with high diffusivity and form a dipole layer at the metal-PS interface causing an additional increase of the energy barrier height at the metal-PS interface. As a result, the reverse current decreases. On the other hand, adsorption of oxygen decreases the energy barrier due to the influence of $\mathrm{O}_{2}^{-}$or $\mathrm{O}^{-}$ions.

Consider now the effect of inorganic polymer film located on the PS surface on the $I-V$ characteristics of the MIS structures based on $p$-type $\mathrm{Si}$ wafers. In presence of the film, the increase of barrier height improves the gas adsorption sensitivity in the forward current mode. External field applied to the diode structure leads to the rearrangement of charges inside the polymer film. It can be assigned to migration of $\mathrm{F}^{-}$ions. Hence, the additional charge of the $\mathrm{F}$ species at the metal-polymer film interface influences the barrier height and, thus, the current level. The uptake of hydrogen on $\mathrm{Pd}-\mathrm{Cu} / \mathrm{Pd}$ top electrodes of the MIS structures was followed by the fluorine species transport to the interface of the metal-PS with polymer film on its top. In this case, the internal electrical field within the polymer film decreases, and an increase of the forward current is observed. In contrast, adsorption of oxygen gas leads to the decrease of the forward current (for $p$ type Si substrate) [16].

On the other hand, the response signal from MIS structure based on mesoporous $\mathrm{Si}$ with pores filled with copper clusters was investigated by means of $C-V$ method. In this case, the influence of adsorption of the gas mixtures of $\mathrm{H}_{2} \mathrm{~S}$ in nitrogen on the flat-band voltage shift $\left(\Delta V_{\mathrm{FB}}\right)$ of the MIS $C-V$ curves was measured by the high-frequency $C-V$ method. These structures demonstrate high sensitivity to $\mathrm{H}_{2} \mathrm{~S}$ gas (Fig. 7). Measurement of the shift $\Delta V_{\mathrm{FB}}$ under the action of adsorption of gas molecules $\left(\mathrm{H}_{2}, \mathrm{H}_{2} \mathrm{~S}\right)$ allow to analyze the adsorption isotherms (Fig. 8).

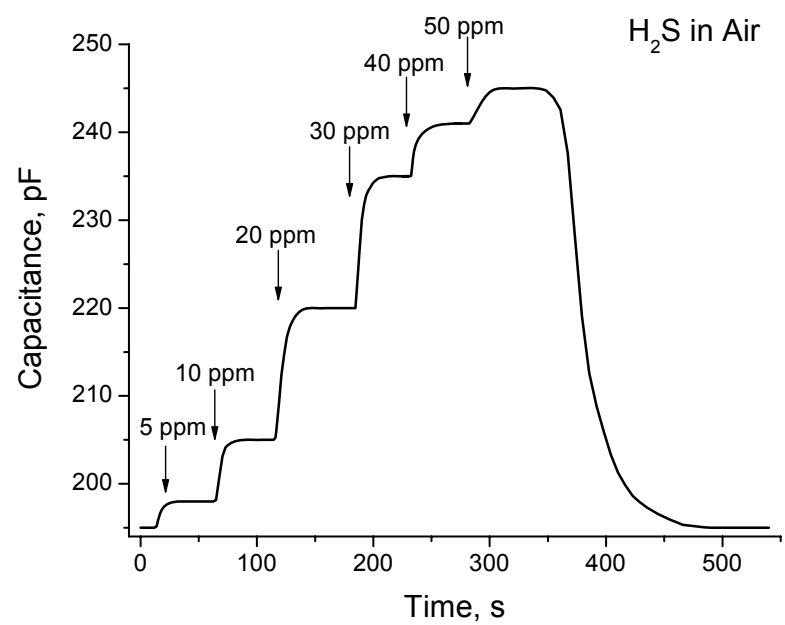

Fig. 7. Kinetic responses of gas sensitive MIS-structures based on meso-PS with pores filled with copper clusters under $\mathrm{H}_{2} \mathrm{~S}$ action. 


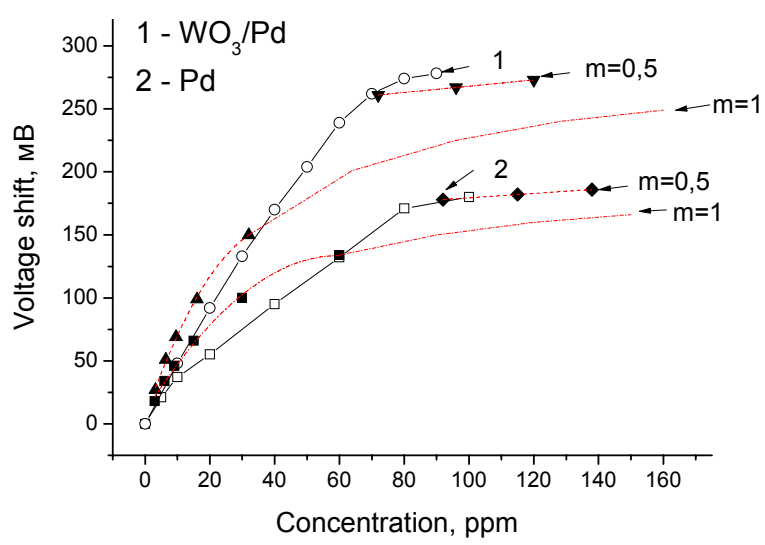

Fig. 8. Isotherm adsorption of $\mathrm{H}_{2} \mathrm{~S}$ on gas sensitive MISstructure with pores filled with $\mathrm{Cu}$ clusters.

The isotherms were analyzed in the framework of the Freundlich theory. The latter gives different initial slopes and index " $m$ " of the dependence for the ordinary molecular $(m=1)$ and decomposition $(m=0.5)$ processes in the case of homogeneous surface:

$\frac{n_{a}}{N_{\max }}=\frac{p^{m}}{\left(1+p / p^{*}\right)^{m}}$

where $n_{a}$ is the number of molecules adsorbed by adsorption centers, $N_{\max }$ - total number of different adsorption centers, $p$ - gas pressure in the chamber, $p^{*}=\frac{B}{A} \exp \left(\frac{\varepsilon_{a}}{k T}\right)-$ characteristic pressure at which the adsorption magnitude is equal to half of the possible maximum, and $\varepsilon_{a}-$ adsorption heat [20-23], respectively. Fig. 8 shows the adsorption isotherms for hydrogen sulfide dissolved in air. They have been obtained using the gas-sensitive structures with various electrode types: $\mathrm{WO}_{3}-\mathrm{Pd}-\mathrm{PS}$ (curve 1 ) and $\mathrm{Pd}-\mathrm{PS}$ (curve 2). Approximations of these isotherms by Freundlich Eq. (7) at different values of $m(=1$ or 0.5$)$ demonstrated good agreement at relatively high pressures in the case of $m=0.5$ and at low pressures in the case of $m=1$. This fact testifies that the hydrogen sulfide molecule undergoes decomposition at high $\mathrm{H}_{2} \mathrm{~S}$ pressures $(p>80 \mathrm{ppm})$, whereas hydrogen sulfide is absorbed in the molecular form at low pressures $(p<$ $25 \mathrm{ppm})$. The sensitivity of the structures with $\mathrm{WO}_{3}-\mathrm{Pd}-$ PS composites with respect to $\mathrm{H}_{2} \mathrm{~S}$ in air is higher than that of the structures with Pd-PS. The voltage shift at the $\Delta V_{\mathrm{FB}}$ level for $\mathrm{H}_{2} \mathrm{~S}$ concentration of $30 \mathrm{ppm}$ in air amounts to $220 \mathrm{mV}$ for the sensitive $\mathrm{WO}_{3}-\mathrm{Pd}-\mathrm{PS}$ layer (Fig. 8, curve 1), which is higher than for the Pd-PS structure ( $\leq 180 \mathrm{mV}$; Fig. 8, curve 2$)$. This is the result of decomposition of $\mathrm{H}_{2} \mathrm{~S}$ molecules adsorbed on the surface of $\mathrm{WO}_{3}$, which gives rise to the strong enhancement of the $\mathrm{H}_{2} \mathrm{~S}$ sensitivity.

\section{Photoluminescence (PL) spectra of porous Si}

Fig. 9 shows the PL spectra of the meso-PS and macroPS layers. In the case of macro-PS, the PL intensity decreases by the factor of $\sim 2$ and the peak position shifts to the shorter wavelength range. It may be associated either with the surface composition or possibly with the surface microstructure and the porosity of the PS layers. The red photoluminescence observed in the meso-PS samples may be related with polymerized hydride. At the same time, the green-blue PL has been found in oxidized microcrystalline silicon in the case of macro-PS layers that is in good accordance with IR-measurements.

The adsorption of glycine (aminoacid) leads to the increase of PL intensity almost two times as well as to the shift of the PL peak to the long-wave region (from 660 to $700 \mathrm{~nm}$ ) caused by the increase in the average size of nc-Si as a result of the recovery process on the PS surface by glycine molecules (Fig. 10) [22].

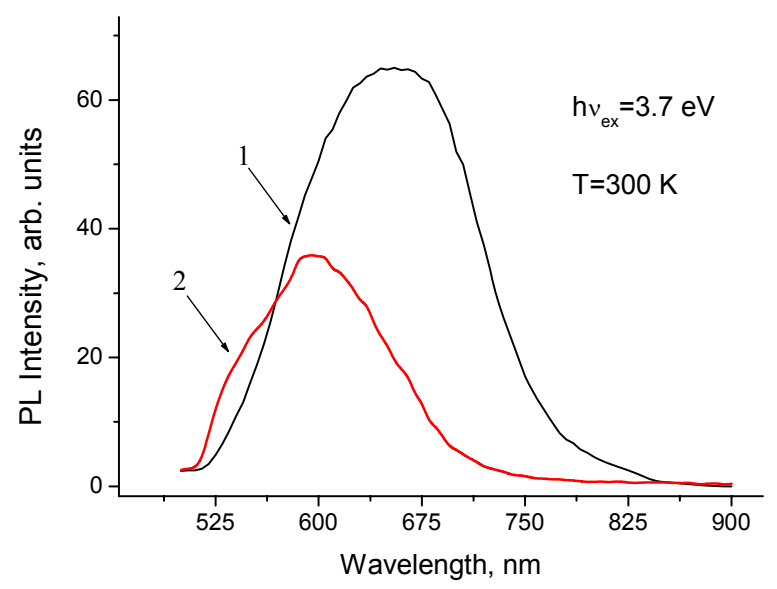

Fig. 9. PL spectra of mesoporous and macroporous silicon on $p$-type $\mathrm{Si}$ wafers.

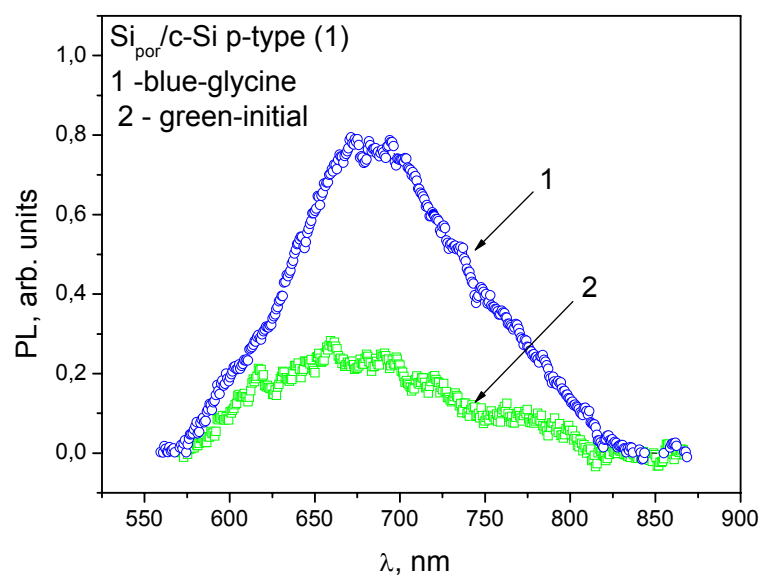

Fig. 10. Effect of glycine adsorption on PL spectra of mesoPS. 
6. Study of the structure of the porous Si layer by using the $X$-ray scanning method

In the case of structural studies, the PS layers were formed on silicon substrates of $p$-type, B-doped with crystallographic orientation of the surface (100) and the resistivity of $7.5 \Omega \cdot \mathrm{cm}$. To fill the pores with copper, $\mathrm{Cu}$ layers deposited on PS surface using the magnetron deposition technique at room temperature followed by annealing at $450{ }^{\circ} \mathrm{C}$ in Ar. The current densities during formation of porous silicon layers were $j_{P S}=3 \mathrm{~mA} / \mathrm{cm}^{2}$ and $j_{P S}=30 \mathrm{~mA} / \mathrm{cm}^{2}$.

The deformation state, structure parameters and dislocation density of the porous silicon were examined using high-resolution X-ray diffraction (HRXRD) with PANalytical X'Pert Pro MRD XL (X'Pert, PANalytical B.V., Almelo) equipped with a $\mathrm{CuK}_{\alpha 1}$ source of radiation $(\lambda=0.15406 \mathrm{~nm})$, standard four-bounce $\mathrm{Ge}(220)$ monochromator and three-bounce (220) channel-cut Ge analyzer. The $\omega / 2 \theta$ XDP of the symmetrical 004 and 111, 333 reflections were measured. The porosity of PS films and their roughness were determined

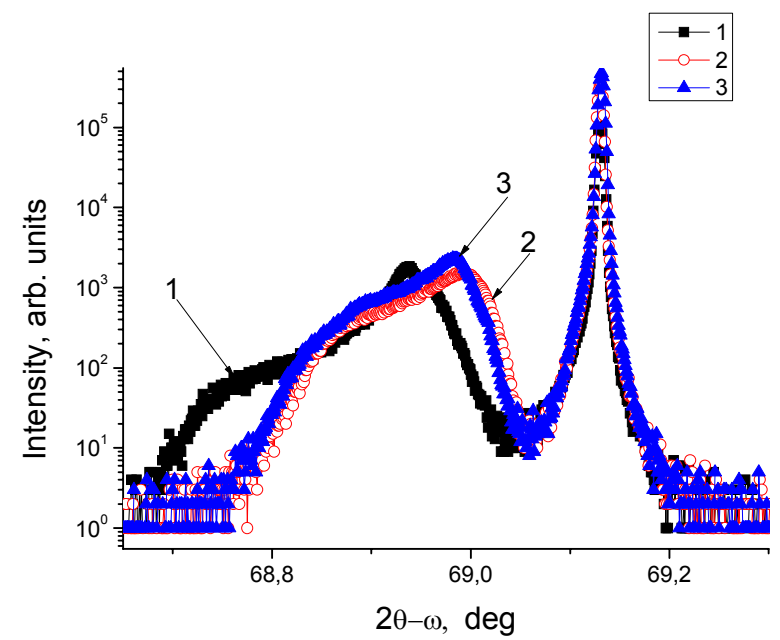

(a) using the XRR method. Diffraction curves for porous silicon using a magnetron method for filling pores with copper, dependences on a current density of 3 and $30 \mathrm{~mA} / \mathrm{cm}^{2}$ are shown in Figs. 11a and $11 \mathrm{~b}$, respectively. As can be seen from Fig. 11a, with formation current of $3 \mathrm{~mA} / \mathrm{cm}^{2}$ the broken layer consists of two layers, with parameters of the lattice larger than the Si lattice parameter, indicating the expansion of the lattice of porous silicon after the incorporation of copper into the pores. While at $30 \mathrm{~mA} / \mathrm{cm}^{2}$ porous layer consists of one layer with less stretching deformation (Fig. 11b). Furthermore, after annealing the halfwidth of peaks from the PS layers both for current density $3 \mathrm{~mA} / \mathrm{cm}^{2}$ and for $30 \mathrm{~mA} / \mathrm{cm}^{2}$ is slightly decreased, indicating to the improvement in defect structure of the porous layer. The porosity of PS films $\rho$ and their roughness were determined by the XRR method. In this case, the densities of the PS films and its porosity in \% were calculated (Table 1). As can be seen from Table 1, a PS layers with smaller pores and surface roughness are formed at a lower current density $\left(j_{P S}=\right.$ $3 \mathrm{~mA} / \mathrm{cm}^{2}$ ) as compared to the samples with the higher current density $\left(j_{P S}=30 \mathrm{~mA} / \mathrm{cm}^{2}\right)$ during PS formation.

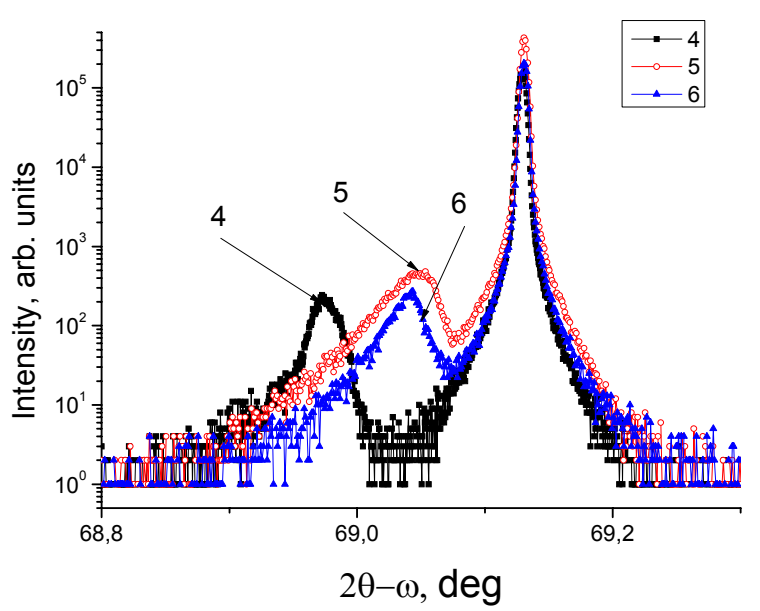

(b)

Fig. 11. X-ray spectra of PS layers obtained using electrochemical etching of $p$-type Si (100) at current densities (a) $j_{P S}=$ $3 \mathrm{~mA} / \mathrm{cm}^{2}$; curves: $\# 1$ - initial curve (without embedded $\mathrm{Cu}$ clusters), no annealed, $\# 2$ - with embedded Cu clusters, no annealed; $\# 3$ - with embedded $\mathrm{Cu}$ clusters, annealed (b) $j_{P S}=30 \mathrm{~mA} / \mathrm{cm}^{2}$, curves: $\# 4$ - initial curve (without embedded Cu clusters), no annealed, \#5 - with embedded $\mathrm{Cu}$ clusters, no annealed; \#6 - with embedded $\mathrm{Cu}$ clusters, annealed, $\mathrm{Cu}$ clusters was embedded by magnetron method to fill the pores with copper.

Table 1 . The porosity of PS layers $(\rho)$ and their roughness (with $\mathrm{Cu}$ clusters embedded using the magnetron method).

\begin{tabular}{|l|c|c|c|}
\hline \multicolumn{1}{|c|}{ Samples } & $j_{P S}, \mathrm{~mA} / \mathrm{cm}^{2}$ & $\rho, \%$ & Roughness, $\mathrm{nm}$ \\
\hline $\begin{array}{l}\text { \# } 1 \text { ( } p \text {-type B-doped (100), without embedded Cu } \\
\text { clusters) no annealed }\end{array}$ & 3 & 46.7 & 1.5 \\
\hline \# 2 (p-type B-doped (100), with Cu clusters) no annealed & 3 & 16.3 & 1.2 \\
\hline \# 3 (p-type B-doped (100), with Cu clusters) annealed & 3 & 14.1 & 0.5 \\
\hline $\begin{array}{l}\text { \# 4 (p-type B-doped (100), without embedded Cu } \\
\text { clusters) no annealed }\end{array}$ & 30 & 60.5 & 2.1 \\
\hline \# 5 (p-type B-doped (100), with Cu clusters) no annealed & 30 & 34.7 & 1.7 \\
\hline$\# 6$ ( $p$-type B-doped (100), with Cu clusters) annealed & 30 & 27.0 & 2 \\
\hline
\end{tabular}

(C) 2017, V. Lashkaryov Institute of Semiconductor Physics, National Academy of Sciences of Ukraine 
7. Modeling of pores formation in Si during electrochemical etching

The model of the pore formation during electrochemical etching of $\mathrm{Si}$ wafers was developed in our previous publications [24]. This model enables studying evolution of pore morphology through all the PS layer thickness in the approximation of an array of cylindrical pores etched along the normal to the wafer surface, by taking into account the reagent and by-products of $\mathrm{Si}$ dissolution transport within the pores $[25,26]$. The generalized model reaction of Si dissolution includes the interaction of holes in Si wafer with hydrofluoric acid molecules and may be presented in the following form:

$2.5 \mathrm{~h}^{+}+\mathrm{HF}+\mathrm{Si} \rightarrow \mathrm{BY}-$ PRODUCTS.
The valence of the reaction (8) equal to 2.5 is chosen, on the one hand, being based on the averaged experimental data, and on the other hand, to make calculations easier.

The system of differential equations describing the kinetics of pore etching in $\mathrm{Si}$ is shown in Table 2, while the respective explanations to the definitions of the parameters of the equations are presented in Table 3 [27]. The concentration of holes in Si wafer prior to the onset of the etching process is set equal to their equilibrium concentration corresponding to the doping level of the Si wafer. During the etching process, the holes were injected from the $x=0$ coordinate into the wafer depth. The holes' current is fixed at this point in agreement with the galvanostatic etching regime. The first boundary condition for holes in Table 1 is written assuming that the flux of holes $J_{p}$ at the point $x=0$ is equal to their diffusion flux to the reaction zone.

Table 2. Dynamic differential equations of the pores formation process.

\begin{tabular}{|c|c|c|}
\hline $\begin{array}{l}\text { Holes transport and balance: } \\
\frac{\partial p}{\partial t}=D_{p} \frac{\partial^{2} p}{\partial x^{2}}-2.5 k p^{2.5} N_{\mathrm{HF}} C_{\text {free }}\end{array}$ & $\begin{array}{l}\text { Boundary conditions: } \\
\frac{\partial p}{\partial x}=\left\{\begin{array}{cc}-\frac{J_{p}}{D_{p}}, & x=0 \\
0, & x=L_{0}\end{array}\right.\end{array}$ & $\begin{array}{l}\text { Initial conditions: } \\
p(x, 0)=p_{0}\end{array}$ \\
\hline $\begin{array}{l}\text { Hydrofluoric acid transport and balance: } \\
\frac{\partial N_{\mathrm{HF}}}{\partial t}=D_{\mathrm{NF}} \frac{\partial^{2} N_{\mathrm{HF}}}{\partial x^{2}}-k p^{2.5} N_{\mathrm{HF}} C_{\text {free }}\end{array}$ & $\begin{array}{l}\left.\frac{\partial N_{\mathrm{HF}}}{\partial x}\right|_{x=0}=0 \\
N_{\mathrm{HF}}\left(L_{0}, t\right)=N_{\mathrm{HF}}^{0}\end{array}$ & $\begin{array}{l}N_{\mathrm{HF}}(x, 0)= \\
=N_{\mathrm{HF}}^{0} \delta\left(x-L_{0}\right)\end{array}$ \\
\hline $\begin{array}{l}\text { Bound by-products balance: } \\
\frac{\partial N_{\text {bound }}}{\partial t}=k p^{2.5} N_{\mathrm{HF}} C_{\text {free }}-a N_{\text {bound }}\end{array}$ & & \\
\hline $\begin{array}{l}\text { Free by-products transport and balance: } \\
\frac{\partial N_{\text {free }}}{\partial t}=D_{\text {free }} \frac{\partial^{2} N_{\text {free }}}{\partial x^{2}}-a N_{\text {bound }}\end{array}$ & & \\
\hline $\begin{array}{l}\text { Pore radius evolution: } \\
\frac{\partial R}{\partial t}=\frac{\Omega k p^{2.5} N_{\mathrm{HF}} C_{\text {free }}}{2 \pi R N_{a}}\end{array}$ & $\begin{array}{l}\left.\frac{\partial N_{\text {free }}}{\partial x}\right|_{x=0}=0 \\
N_{\text {free }}\left(L_{0}, t\right)=0\end{array}$ & \\
\hline $\begin{array}{l}\text { Reaction places evolution: } \\
\frac{\partial N_{t}}{\partial t}=2 \pi n_{t} N_{a} \frac{\partial R}{\partial t}\end{array}$ & & \\
\hline $\begin{array}{l}\text { Free places evolution: } \\
C_{\text {free }}=1-\frac{N_{\text {bound }}}{N_{t}}\end{array}$ & & \\
\hline
\end{tabular}


Table 3. Definitions for Si parameters.

\begin{tabular}{|c|c|}
\hline Symbol & Parameter description \\
\hline$p$ & holes concentration in the wafer \\
\hline$N_{\mathrm{HF}}, N_{\text {bound }}, N_{\text {free }}$ & HF, bound by-products and free by-products concentration, respectively \\
\hline$n_{t}, N_{t}, C_{\text {free }}$ & $\begin{array}{l}\text { surface density, total concentration and free places on pore walls portion where Si dissolution can } \\
\text { take place }\end{array}$ \\
\hline$R$ & pore radius \\
\hline$N_{a}$ & surface density of the pores on wafer surface \\
\hline$\Omega$ & Si atomic volume \\
\hline$k$ & reaction constant \\
\hline$a$ & desorption coefficient of bound by-products of Si dissolution \\
\hline$D_{p}, D_{\mathrm{HF}}, D_{\text {free }}$ & hole, HF molecules and free by-products of Si dissolution diffusitivities \\
\hline$p_{0}$ & majority carriers (holes) concentration in $\mathrm{Si}$ wafer \\
\hline$N_{\mathrm{HF}}^{0}$ & bulk electrolyte HF concentration \\
\hline
\end{tabular}

The supply of HF molecules in the reaction zone takes place by diffusion from the bulk of electrolyte, where the concentration of HF molecules is set to a fixed value during the whole anodization process. The dissolution rate of $\mathrm{Si}$ and, hence, the pore radius kinetics depends on the local HF concentration as well as is additionally determined by the pores' surface density, $N_{a}$, and the degree of passivation of internal pore surface by the bound by-products, $C_{\text {free }}$.

The modeled lengths of pores versus time of electrochemical etching for different anodization current densities are shown in Fig. 12. The results demonstrate linear dependence of the pore length on the etching time during the initial process stages with subsequent slowing down at prolonged etching. Higher current densities lead to earlier transition to the sub-linear dependence due to the diffusion-limited supply of HF molecules to the reaction zones deep inside the pores. In addition, linear dependences of pore growth rate on the concentration of $\mathrm{HF}$ in the electrolyte as well as on the anodization current density are obtained.

Comparison of the results of the kinetic modeling of pore growth process during the electrochemical etching of Si wafers with respective experimental data show their full consistency at a qualitative level. The thickness of the porous $\mathrm{Si}$ film is known to increase linearly with the increase of anodization time at the first stage of etching, while the pore growth slows down at later stages due to the decrease of electrolyte concentration inside the pores [28]. Moreover, the rate of pore growth also linearly depends on the electrolyte concentration, and for $p$-type silicon it is proportional to the anodization current density.
Analysis of the pore profiles obtained by the kinetic modeling (see Fig. 13) reveals formation of cylindrical pores at smaller current densities (up to $\sim 20 \mathrm{~mA} / \mathrm{cm}^{2}$ in our calculations). Formation of cylindrical pores corresponds to Si dissolution reaction limited by the supply of holes to the reaction zone. At higher values of $J_{p}$, the supply of HF molecules to the reaction zone by means of diffusion begins limiting the electrochemical reaction, which leads to the preferential etching of Si closer to the surface and to formation of "bottle-like" pores. Finally, the merging of the neighbour pores starts, which corresponds to the experimentally observed electropolishing stage.

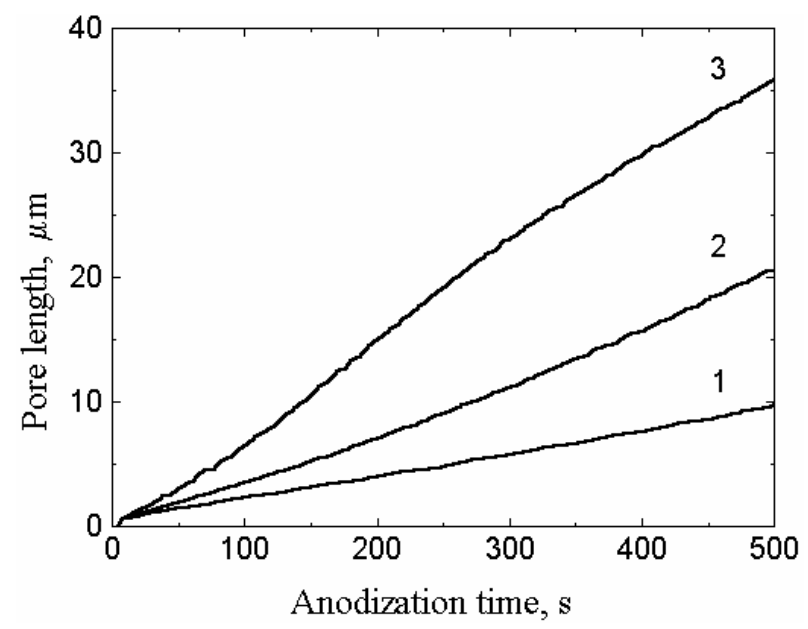

Fig. 12. Dependence of the pore length on etching time. HF concentration in the electrolyte $-40 \%, \mathrm{Si}$ wafer resistivity $5 \Omega \cdot \mathrm{cm}$. Anodization current density, $\mathrm{mA} / \mathrm{cm}^{2}: 1-10,2-20$, $3-40$. 


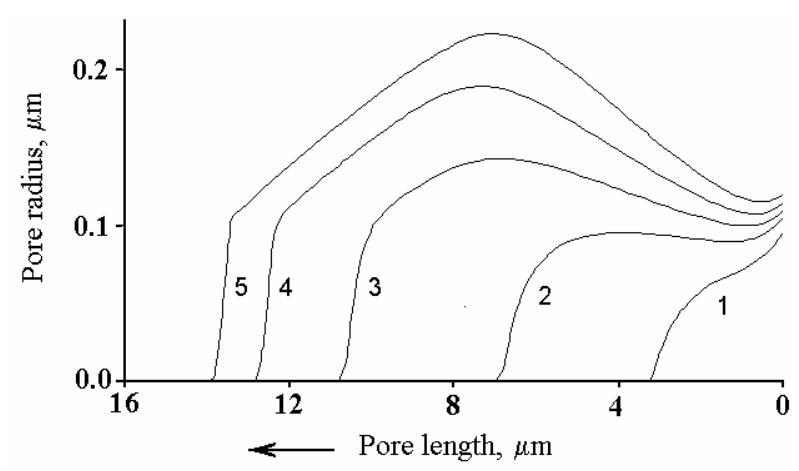

Fig. 13. Simulated profiles of pores etched at various current densities. HF concentration in the electrolyte $-30 \%$, Si wafer resistivity $-14 \Omega \cdot \mathrm{cm}$. The anodization current density, $\mathrm{mA} / \mathrm{cm}^{2}: 1-10,2-20,3-30,4-40,5-50$.

\section{Conclusion}

In conclusion, we have presented the review of the results of porous silicon properties such as morphology and microstructure, chemical composition, photoluminescence and adsorption. In this study, we demonstrated the effect of the electrolyte composition (concentration values of HF) and density current on porous silicon formation (the structure and chemical composition) for $p$-type silicon substrates. PS layers were formed on crystalline silicon wafers of (100) crystallographic orientation using electrochemical etching in the mixture of hydrofluoric acid and ethanol. It was found that the polymerized mesoporous silicon films were formed at high HF concentrations, whereas the macroporous Si layers with oxidized microcrystalline silicon have been formed at low HF concentrations on $p$ type silicon substrates. FTIR spectrum measured within the range of wavenumbers from 400 up to $4000 \mathrm{~cm}^{-1}$ exhibit the polymerized hydride films $(\mathrm{SiH})_{\mathrm{n}}$ on the meso-PS surface. At the same time, silicon oxide was detected on the macro-PS surface. Photoluminescence studies demonstrate the red photoluminescence in the case of the polymerized $\left(\mathrm{SiH}_{\mathrm{n}}, n=1 \ldots 3\right)$ mesoporous silicon films (passivation effect). Whereas, the oxidized macroporous silicon layers with microcrystallites exhibit the green-blue photoluminescence (quantum-confinement effect).

Basic parameters of the PS layers such as average pore size ( 2 to $8 \mathrm{~nm}$ for meso-PS and 500 to $3000 \mathrm{~nm}$ for the macro-PS), porosity ( $60 \%$ for meso-PS and $86 \%$ for macro-PS), refraction index ( $n=1.75$ for meso-PS), PS layer thickness (5 to $20 \mu \mathrm{m}$ ) have been found, too.

Gas sensitive MIS structures based on mesoporous silicon layers with top catalytically active $\left(\mathrm{Pd}, \mathrm{Cu}, \mathrm{WO}_{3}\right)$ electrodes have been formed to study the adsorption properties. Gas sensitivity of these structures with top catalytic active electrodes on PS and with pores doped with $\mathrm{Cu} / \mathrm{WO}_{3}$ clusters have been studied by the analysis of $I-V$ characteristics and by high-frequency $C-V$ method under the action of $\mathrm{H}_{2} \mathrm{~S}$ and $\mathrm{H}_{2}$.
The theoretical model describing the kinetics of pores formation in Si during the electrochemical etching has been presented. The model takes into account a simplified way of transport of reagent and by-products of Si dissolution inside the pores, making it possible to model the morphology evolution through all the porous layer thickness as well as to explain the mechanisms of a number of experimentally observed effects.

\section{Acknowledgments}

This investigation was carried out under financial support of National Academy of Sciences of Ukraine (Projects No. 23-2017, No. III-5-16, No. III-10-15) and Research Council of Lithuania (Grant No. TAP-LU-52016).

\section{References}

1. Canham T.I. Silicon quantum wire array fabrication by electrochemical and chemical dissolution of wafers. Appl. Phys. Lett. 1990. 57. P. 1046.

2. Mak K.F., Lee C., Hone J., Shan J., and Heinz T.F. Atomically thin $\mathrm{MoS}_{2}$ : a new direct gap semiconductor. Phys. Rev. Lett. 2010. 105. P. 136805.

3. G. Juska, A. Medvid', V. Gulbinas. Initial Charge Carrier Dynamics in Porous Silicon Revealed by Time Resolved Fluorescence and Transient Reflectivity// Physica Status Solidi (A) Applications and Materials 207(1):188 - 193 (2009).

4. Cullis A.G., Canham L.T., and Calcott P.D.J. The structural and luminescence properties of porous silicon. J. Appl. Phys. 1997. 82. P. 909.

5. Bisi O., Ossicini S., and Pavesi L. Porous silicon: a quantum sponge structure for silicon based optoelectronics. Surf. Sci. Rep. 2000. 38. P. 1.

6. Cullis A.G. and Canham L.T. Visible light emission due to quantum size effect in highly porous crystalline silicon. Nature Lett. 1991. 353. P. 335 .

7. Ledoux G., Guillois O., Porterat D., Reynaud C., Huisken F., Kohn B., and Paillard V. Photoluminescence properties of silicon nanocrystals as a function of their size. Phys. Rev. B. 2000. 62. P. 15942.

8. Smith R.L. and Collins S.D. Porous silicon formation mechanism. J. Appl. Phys. 1992. 71. P. R1.

9. Kleimann P., Linnros J., and Juhasz R. Formation of three-dimensional microstructures by electrochemical etching of silicon. Appl. Phys. Lett. 2001. 79. P. 1727.

10. Searson P.C. and Zhang X.G. The anodic dissolution of silicon in HF solutions. J. Electrochem. Soc. 1990. 137. P. 2539. 
11. Memming R. and Schwandt G. Anodic dissolution of silicon in hydrofluoric acid solutions. Surf. Sci. 1966. 4. P. 109.

12. Propst E.K. and Kohl P.A. The electrochemical oxidation of silicon and formation of porous silicon in acetonitrile. J. Electrochem. Soc. 1994. 141. P. 1006.

13. Foll H., Carstensen J.U., and Frey S. Porous and nanoporous semiconductor and emerging applications. J. Nanomater. 2006. 2006. P. 1.

14. Manilov A.I., Alekseev S.A., Scryshevsky V.A., Litvineneko S.V., Kuznetsov G.V., and Lysenko V. J. Alloys and Compounds. 2010. 492. P. 466-472.

15. Smyntyna V.A. Semiconductor Materials for Gas Sensors, Chap. 3. Ed. V.A. Smyntyna. P. 35-46. New York: Nova Science Publishers, 2013.

16. Litovchenko V.G., Gorbanyuk T.I., Solntsev V.S., and Evtukh A.A. Mechanism of hydrogen, oxygen and humidity sensing by $\mathrm{Cu} / \mathrm{Pd}$-porous siliconsilicon structures. Appl. Surf. Sci. 2004. 234. P. 262.

17. Gorbanyuk T.I., Evtukh A.A., Litovchenko V.G., Solntsev V.S., and Pakhlov E.M. Porous silicon microstructure and composition characterization depending on the formation conditions. Thin Solid Films. 2006. 495. P. 134.

18. Okayamaa H., Fukamia K., Plugarub R., Sakkaa T., and Ogataa Y.H. Ordering and disordering of macropores formed in rrepatterned p-type silicon. J. Electrochem. Soc. 2010. 157. P. D54.

19. Gorbanyuk T.I., Evtukh A.A., Litovchenko V.G., Solntsev V.S. Modified MIS-structure based on nanoporous silicon with enhanced sensitivity to the hydrogen containing gases. phys. status solidi (c). 2008. 5. P. 3655.

20. Gorbanyuk T.I., Evtukh A.A., Litovchenko V.G., Solntsev V.S. Nanoporous silicon doped by $\mathrm{Cu}$ for gas-sensing applications // Physica E 38, p. 211 (2007).

21. Litovchenko V.G., Gorbanyuk T.I., Ptushinskii Yu.G., and Kanash O.V. Gas sensing properties of the nanosized $\mathrm{Pd}$ and $\mathrm{CuxPd}$ layers. Physical Properties of Nanosystems, NATO Science for Peace and Security Series B: Physics and Biophysics. 2011. P. 325.

22. Litovchenko V.G., Gorbanyuk T.I., Solntsev V.S New adsorption active nanoclusters for ecological monitoring, in: Nanodevices and Nanomaterials for Ecological Security, Ed. A. Kiv. Springer, 2013, P. 297-306.

23. Litovchenko V.G., Gorbanyuk T.I. Mechanism of influence of aminoacid adsorption on photoluminescence of nanoporous silicon. Nanotechnology in the Security Systems, NATO Science for Peace and Security Series C: Environmental Security. Springer Science, 2015. P. 257-266.

24. Litovchenko V.G., Gorbanyuk T.I., Solntsev V.S. Mechanism of adsorption-catalytic activity at the nanostructured surface of silicon doped with clusters of transition metals and their oxides. Ukr. J. Phys. 2017. 62. P. 605.

25. Efremov A.A., Litovchenko V.G., and Sarikov A.V. The formation of the low-dimensional porous silicon-based structures with extremely high exciton binding energy. Mater. Sci. Eng. C. 2003. 23. P. 165-170.

26. Evtukh A.A., Litovchenko V.G., Litvin Yu. M., Efremov A. A., Rassamakin Yu.V., Sarikov A.V., and Fedin D.V. Porous silicon as a material for enhancement of electron field emission. Phys. Low-Dim. Struct. 2001. N 1/2. P. 65-72.

27. Efremov A.A. and Sarikov A.V. Computer modelling of the porous silicon formation process. Proc. XVI Open scientific and technical conference of young scientists and specialists of the Karpenko Physico-Mechanical Institute of NAS of Ukraine (YSC-2001), Lviv, May 18-22, 2001, P. 47-50.

28. Labunov V.A., Bondarenko V.P., and Borisenko V.E. Porous silicon in semiconductor electronics. Zarubezhnaya Elektronnaya Tekhnika. 1978. N 8. P. 3-48 (in Russian). 